\title{
Correction to: Thermal error prediction of machine tool spindle using segment fusion LSSVM
}

\author{
Feng $\operatorname{Tan}^{1} \cdot$ Guofu Yin ${ }^{2} \cdot$ Kai Zheng ${ }^{1} \cdot$ Xin Wang ${ }^{1}$ \\ Published online: 10 June 2021 \\ (C) Springer-Verlag London Ltd., part of Springer Nature 2021
}

Correction to: The International Journal of Advanced Manufacturing Technology.

https://doi.org/10.1007/s00170-021-07066-7

The original article contained a mistakes in the affiliations:

Feng $\operatorname{Tan}^{1} \&$ Guofu Yin $^{2} \&$ Kai Zheng ${ }^{3} \&$ Xin Wang ${ }^{3}$

1. School of Computer Science and Technology, university electronic Science and Technology of China, 611731 Chengdu, People's Republic of China

2. School of Mechanical Engineering, Sichuan University

Chengdu 610065, People's Republic of China

3. School of Advanced Manufacturing Engineering, Chongqing University of Posts and Telecommunications, Chongqing 400065, People's Republic of China
The correct affiliations are shown below:

Feng $\operatorname{Tan}^{1} \&$ Guofu Yin $^{2} \&$ Kai Zheng ${ }^{1} \&$ Xin Wang ${ }^{1}$

1. School of Advanced Manufacturing Engineering, Chongqing University of Posts and Telecommunications, Chongqing 400065, People's Republic of China

2. School of Mechanical Engineering, Sichuan University Chengdu 610065, People's Republic of China

The original article has been corrected.

Publisher's note Springer Nature remains neutral with regard to jurisdictional claims in published maps and institutional affiliations.

The online version of the original article can be found at https://doi.org/ 10.1007/s00170-021-07066-7

Feng Tan

itanfeng@qq.com

1 School of Advanced Manufacturing Engineering, Chongqing University of Posts and Telecommunications, Chongqing 400065, People's Republic of China

2 School of Mechanical Engineering, Sichuan University, Chengdu 610065, People's Republic of China 